tumours of the right ovary is interesting. Possibly the endocrinological environment of the more frequently ovulating right ovary has an adverse effect on metastatic potential.

I thank Dr Doris Campbell for statistical advice, Dr W T Fullerton and the Grampian oncology research project for the data set, and Mrs Sheila Mearns for typing the manuscript.
Incessant ovulation and ovarian cancer: a critical approach. Int $\mathcal{f}$ Epidemiol $1983 ; 12: 161-4$

2 Beral V. The epidemiology of ovarian cancer. In: Sharp F, Soutter WP, eds. Ovarian cancer-the way ahead. Chichester: Wiley, 1987:21-8.

3 The cancer and steroid hormone study of the Centers for Disease Control and the National Institute of Child Health and Human Development. The the Nationa lnstic of Chld Healh and Human Development. The reduction in risk of ovarian

4 Potashink G, Insler V, Meizner I, Stenberg M. Frequency, sequence, and side of ovulation in women menstruating normally. BrMed f 1987;294:219.

5 Fishel S, Jackson P. Follicular stimulation for high tech pregnancies; are we playing it safe? Br Med f 1989;299:309-11.
.

(Accepted 22 fune 1990)

\title{
Risk of HIV infection among clients of the sex industry in Scotland
}

\author{
Ruth Morgan Thomas, Martin A Plant, \\ Moira L Plant, Jill Sales
}

Alcohol Research Group, Department of Psychiatry, University of Edinburgh, Edinburgh EH10 5HF Ruth Morgan Thomas, BA, research associate

Martin A Plant, PHD, director Moira L Plant, PHD, research fellow

Jill Sales, MSC, research associate

Correspondence to: Ms Morgan Thomas.

BrMed f 1990;301:525
Concern about the connection between prostitution and sexually transmitted diseases has been heightened by the AIDS epidemic and by the fact that some of those who buy and sell sexual services are heavy users of alcohol and illicit drugs. ${ }^{1-3}$ To examine the risks of HIV infection in relation to the sex industry a research project was initiated in Edinburgh; it was conducted among both those buying and those selling sexual services.

\section{Subjects, methods, and results}

A client was defined as someone who had paid for physical sexual services, and a sex worker as a person who provided such services for payment. This study elicited data from both clients and sex workers. The information obtained from the sex workers has been described elsewhere..$^{2-4}$

Data on over 300 variables were elicited from clients by an interview. Respondents were contacted by a "snowballing" technique, whereby 10 interviewers approached sex workers who had been contacted earlier, ${ }^{2}$ who introduced them to clients. The clients were not a representative group, and this method probably resulted in well known or regular clients being overrepresented. This paper relates to 209 clients who were interviewed during 1988 and 1989.

Two hundred and six of those interviewed were men and three were women. Their age range was 18-60. The mean age of the men was 33.2 years and that of the women 27.7 years. One hundred and seventy two of the male clients reported having contacted only female sex workers, 26 had contacted only male sex workers, and five had contacted both male and female sex workers. Two of the female clients had contacted male sex workers and the third had contacted both male and female sex workers. The number of different sex workers whom clients had reportedly contacted in the previous year ranged from one to 100 (median $=5$, mode $=3$ ). Only 21 reported having contact with only one, regular sex worker.

One hundred and twenty one clients reported that they asked to use condoms for penetrative intercourse. About a third of clients who had contact with male sex workers sometimes refused to use condoms. Only one in eight of the clients of female sex workers reported refusing to use condoms. Men having anal sex with male sex workers reported a higher level of use of condoms than did men who had anal intercourse with female sex workers (table). Almost a third of the study group reported that they had paid more for unprotected than for protected sex. Of those who used condoms, male clients of male sex workers and clients of both male and female sex workers were more likely than clients of only female sex workers to report failure of condoms $(10 / 17$ and $1 / 2$ respectively $v 11 / 92)$. In contrast, only a quarter of respondents (23/87) who reported having a regular unpaid sexual partner reported using condoms with that person.

Use of condoms during penetrative intercourse with sex workers in previous year. Figures are estimated numbers (percentages) of occasions when condoms were used

\begin{tabular}{lccc}
\hline & \multicolumn{2}{c}{ Male clients } & \\
\cline { 2 - 3 } & $\begin{array}{c}\text { Male sex worker } \\
(\mathbf{n}=21)\end{array}$ & $\begin{array}{c}\text { Female sex worker } \\
(\mathbf{n}=167)\end{array}$ & $\begin{array}{c}\text { Female clients } \\
(\mathbf{n}=2)\end{array}$ \\
\hline $\begin{array}{l}\text { Anal intercourse } \\
\text { Vaginal intercourse }\end{array}$ & $\begin{array}{c}618 / 685(90 \cdot 2) \\
\text { Not applicable }\end{array}$ & $\begin{array}{c}31 / 130 \\
(23 \cdot 8)\end{array}$ & $\begin{array}{c}30 / 31(96 \cdot 8) \\
\text { No data }\end{array}$ \\
\hline
\end{tabular}

Twenty six respondents ( 25 men, one woman) reported having injected drugs, of whom 16 reported having shared injecting equipment after 1980.

Fifty four respondents reported having been tested for HIV infection, of whom seven stated that the result had been positive. All seven had injected drugs.

\section{Comment}

These results are broadly consistent with information from studies of sex workers in several countries. ${ }^{3}$ A study of clients of sex workers in Birmingham also found that about a third reported having persuaded sex workers to engage in unprotected intercourse $(H$ Kinnell, unpublished data).

Sex workers and their clients are important targets for information on preventing HIV infection. Strategies must be implemented to impart health education to these people. Action is also urgently needed to increase the availability of strengthened condoms for anal intercourse. There is little evidence that HIV infection in developed countries has been spread by prostitution. Even so, evidence suggests that there is a risk not only of sex workers infecting clients but also of clients infecting sex workers.

This study was funded by the Medical Research Council. Additional support was provided by the Bill Kenyon Education Trust, the Scottish Health Education Group, the Scotch Whisky Association, and an anonymous charity. We thank Mrs Val Mannings and Mrs Janis Nichol for processing the manuscript.

1 Plant ML, Plant MA, Peck DF, Setters J. The sex industry, alcohol and illicit drugs: implications for the spread of HIV infection. Br f Addict 1989;84:53-9. 2 Thomas RM, Plant MA, Plant ML, Sales DE. Risk of AIDS among workers in the "sex industry": some initial results from a Scottish study. Br Med $\mathcal{F}$ 1989;299:148-9.

3 Plant MA, ed. AIDS, drugs and prostitution. London: Tavistock/Routledge, 1990.

4 Plant ML, Plant MA, Thomas RM. Alcohol, AIDS risks and commercial sex: some preliminary results from Scottish study. Drug Alcohol Depend $1990 ; 25: 51-5$.

(Accepted 1 June 1990) 